\title{
A NORMATIVIDADE DA TEORIA REPUBLICANA DA JUSTIÇA
}

\author{
Alberto Paulo Neto ${ }^{1}$ \\ Pontifícia Universidade Católica do Paraná (PUCPR) \\ Universidade de São Paulo (USP) \\ https://orcid.org/0000-0003-2322-1984
}

\begin{abstract}
RESUMO:
O fundamento normativo da concepção republicana de justiça é a liberdade como não-dominação. Esse conceito de liberdade política compreende as relações sociais em igualdade de poder. A nãodominação representa a condição social de não estar submisso a capacidade de interferência arbitrária de outrem. A liberdade republicana pressupõe o desenvolvimento das capacidades humanas em sua plenitude. O potencial de desenvolvimento das capacidades humanas deve ser protegido pela estrutura jurídica do Estado. O Estado tem a função de equiparar os desníveis de bens e recursos dos indivíduos com a sua estrutura institucional. Ele atua para oferecer as condições necessárias, os direitos e as liberdades básicas, aos indivíduos em sua vida social e política. A perspectiva republicana de Philip Pettit enseja realizar a dedução normativa da liberdade republicana e demonstrar que a teoria da justiça tem que pressupor os recursos necessários para o desenvolvimento da vida humana em sua condição de igualdade e liberdade. A estruturação democrática da sociedade pressupõe o estabelecimento de relações sociais que se caracterizem pelo status social de não-dominação.
\end{abstract}

PALAVRAS-CHAVE: Republicanismo; Normatividade; Justiça; Philip Pettit.

\section{THE NORMATIVITY OF THE REPUBLICAN THEORY OF JUSTICE}

\begin{abstract}
:
The normative basis of the republican conception of justice is freedom as non-domination. This concept of political freedom comprises social relations in equality of power. Non-domination represents the social condition of not being submissive to the capacity of arbitrary interference of others. Republican freedom presupposes the development of human capabilities in their fullness. The potential for human capacity development must be protected by the legal structure of the State. The State has the function of equating the differences of individuals' assets and resources with their institutional structure. It acts to offer the necessary conditions, rights and basic liberties, to individuals in their social and political life. The Republican perspective of Philip Pettit leads to the normative deduction of republican liberty and to demonstrating that the theory of justice has to presuppose the resources necessary for the development of human life in its condition of equality and freedom. The democratic structuring of society presupposes the establishment of social relations that are characterized by the social status of non-domination.
\end{abstract}

KEYWORDS: Republicanism; Normativity; Justice; Philip Pettit.

\footnotetext{
${ }^{1}$ Doutor em Filosofia pela Universidade de São Paulo (USP), São Paulo - Brasil e realiza o estágio de pós-doutorado na Universidade de São Paulo (USP), Brasil com o Projeto de Pesquisa "Democracia contestatória e Justiça social". Líder do Grupo de Pesquisa "Justiça e Direitos fundamentais" (CNPq/PUCPR). Professor da Pontifícia Universidade Católica do Paraná (PUCPR), Paraná Brasil. A pesquisa está inserida no Projeto de Pesquisa básica e aplicada "Republicanismo, Democracia e Justiça social" e foi realizada com o apoio da Fundação Araucária (Chamada Pública 09/2016). E-mail: apnsophos@yahoo.com.br.
}

NETO, Alberto Paulo. A normatividade da teoria republicana da justiça. Griot : Revista de Filosofia, Amargosa, Bahia, v.16, n.2, p.115-131, dezembro/2017. 
(...) a liberdade, que não se estriba em ter um bom amo, mas em não o ter (Cícero, Da República, Livro II, XXII).

A matriz romana do pensamento republicano estabeleceu a justiça como sendo a estrutura jurídica de igualdade entre os cidadãos. Na filosofia de Cícero, o status jurídico seria a liberdade de escolha e a proteção jurídica ${ }^{2}$. A justiça não é definida de forma eidética como realizou a politeia platônica (Cf. HOLTON, 1993, p. 159). Ela se desenvolve na evolução histórica da República. A justiça possui a estrutura dialógica, tal como a organização da obra $D e$ Re publica de Cícero, e se insere nas relações sociais e nas instituições. Essa estrutura literária estabelece a relação entre a filosofia e a civitas ou entre os pressupostos normativos e os problemas sociais da cidade. $O$ filósofo romano se esforçou pela releitura da história jurídica romana com o teor normativo da filosofia. Ele possibilitou a compreensão do modo de vida romano em acordo com a concepção universalista do direito natural (Cf. FOX, 2007, p. 80; MORFORD, 2002, p. 75; STROH, 2008, p. 54, ZETZEL, 1999, p. XVII).

Nesse enredo jurídico-filosófico, a liberdade civil tem centralidade na República e nas formas de governo analisadas por Cícero. A liberdade política é representada pela capacidade dos cidadãos em terem a independência em suas escolhas e a proteção contra as relações sociais arbitrárias na civitas e para além das fronteiras (Cf. DIGESER, 2004, p. 6).

Na contemporaneidade filosófica, Philip Pettit tem se destacado por fornecer a densidade normativa ao conceito republicano de liberdade política. A teoria republicana da justiça tem objetivo de garantir o status social de igualdade entre os cidadãos. Como veremos, a teoria política de Philip Pettit fundamenta que o Estado democrático de direito deve possibilitar o desfruto da igual liberdade como nãodominação. O Estado tem que proporcionar a proteção contra as formas de dominação privada.

Já na clássica Roma republicana, o mal da sujeição à vontade dos outros, quer seja a sujeição ou não à interferência real, foi identificado e indiciado como a icônica organização política que deve libertar as pessoas, em particular, daqueles em posição privilegiada aos cidadãos. Ele foi descrito como o mal de estar sujeito a um mestre, ou dominus - sofrimento (dominatio) - e foi contrastado com o bem da libertas, ou "liberdade". A sabedoria aceita era de que as pessoas poderiam desfrutar da liberdade, tanto em relação ao outro e à coletividade, apenas por serem investidas com o poder e o status dos civis, ou 'cidadão'. Ser uma pessoa livre se tornou o sinônimo de ser capacitado suficientemente para ficar em condições de igualdade com os outros, como um cidadão entre os cidadãos (PETTIT, 2012, p. 2).

A liberdade como não-dominação, segundo Pettit (2012), é a capacidade de escolha sem qualquer intromissão ou sujeição à vontade alheia. Essa capacidade não

\footnotetext{
${ }^{2}$ Segundo Honohan (2002, p. 36): “Em Roma, os cidadãos não eram distinguidos pelo seu direito de participar, mas pelo seu status jurídico, ou o direito de reclamar a proteção da lei. A liberdade (libertas) não significava a igualdade na participação ou a automática liberdade de expressão, como em Atenas".
}

NETO, Alberto Paulo. A normatividade da teoria republicana da justiça. Griot : Revista de Filosofia, Amargosa, 
poderia ser reduzida pelo poder que outro tivesse em interferir, impedir ou frustrar a livre-escolha. A liberdade republicana, como princípio normativo, pressupõe a garantia de recursos necessários para que os indivíduos tenham a capacidade de realizar as suas decisões em igualdade com aqueles que possuem as condições mais favoráveis. A não-dominação significa não estar à mercê da vontade de outrem ou dependente da filantropia ou caridade para a realização do projeto pessoal de vida. “É possível conceituar a liberdade política como ausência de dominação, argumentando que uma pessoa é livre na medida em que os outros não estão acima dela ou tenham a capacidade de interferir na sua vontade com relativa impunidade em seus assuntos" (PETTIT, 2005, p. 87).

Ela implica que o indivíduo seja sui juris, isto é, ele deve ter a independência perante qualquer pessoa que requeira submissão. A condição sui juris requer as condições de realizar e ser responsável pelas próprias escolhas. A justiça ocorre nas relações entre os cidadãos e segundo o ideal regulativo da liberdade. Como será apresentada, a normatividade da teoria republicana da justiça está fundamentada nos princípios e normas de justiça (1), as demandas desta concepção de justiça (2) e o valor do reconhecimento público das leis para assegurar as liberdades básicas (3) (Cf. PETTIT, 2012, p. 122).

\section{O princípio normativo da teoria republicana da justiça}

(...) sem uma suprema justiça, não se pode reger de modo algum a coisa pública (Cícero, Da República, Livro II, XLI).

A abordagem republicana da justiça considera a liberdade como nãodominação é o único fundamento para a igualdade nas relações sociais. A liberdade como não-dominação é a orientação para a assegurar a igualdade social aos cidadãos mediante o estabelecimento de normas jurídicas. Pettit (2012) argumenta a teoria republicana da justiça é mais exigente do que o modelo rawlsiano de justiça porque o modelo republicano fundamenta a justiça somente no conceito de liberdade e não necessita ser complementado com outro princípio normativo ${ }^{3}$.

A concepção republicana de justiça possui a característica minimalista de justificação dos direitos que serão imprescindíveis para assegurar a realização dos

3 Nas palavras de Pettit (2012, p. 123): “As teorias contemporâneas da justiça dão importância à liberdade, mas elas exigem pouco dos requisitos da igual liberdade e são complementadas com outras fontes - como, por exemplo, o segundo princípio de Rawls - para corrigir as demandas da justiça". Em diversos momentos da obra "On the people's terms: a republican theory and model of democracy", Pettit (2012) indica que a sua concepção de justiça se diferencia da concepção rawlsiana. Primeiramente o modelo republicano realiza a distinção entre justiça e legitimidade política (PETTIT, 2012, p. 75-77) e se fundamenta somente no princípio da liberdade, ao contrário, o modelo do liberalismo político postula a prioridade do princípio da igual liberdade e complementa com o princípio da diferença. Como veremos, Pettit argumenta que a liberdade republicana é o princípio suficiente para garantir a liberdade e igualdade entre os cidadãos. "A justiça e a legitimidade, argumenta ele, são os dois domínios normativos em que a filosofia política é dividida, e ambos devem ser governados pelo supremo valor da liberdade como não-dominação. A justiça, em suma, é o domínio que regula as relações horizontais entre cidadãos ou indivíduos que vivem juntos em igualdade de condições, enquanto a legitimidade é o domínio que envolve a relação vertical entre esses cidadãos e suas instituições governantes" (MARTÍ \& SELEME, 2015, p. 25).

NETO, Alberto Paulo. A normatividade da teoria republicana da justiça. Griot : Revista de Filosofia, Amargosa, 
projetos de vida em liberdade. Essa compreensão minimalista, em comparação com outras teorias da justiça mais expansivas e igualitárias, pretende fornecer os recursos e proteções para a manutenção da condição social de não-dominação ${ }^{4}$. De acordo com Joshua Cohen (2004), a estratégia minimalista de justificação poderá conduzir ao avanço das proteções e segurança aos indivíduos que tenham sofrido a violação dos seus direitos como seres humanos. "O minimalismo pode ser mais do que nós podemos razoavelmente esperar. Mas a esperança não é a mesma expectativa. E o minimalismo dos direitos humanos desenha os limites da esperança por muito pouco" (COHEN, 2004, p. 191). O objetivo é garantir as demandas sociais e políticas que sejam necessárias para qualquer estilo de vida e para as diferentes concepções de bem em liberdade ${ }^{5}$. Nesta concepção de justificação de seus pressupostos, o princípio normativo que será arguido fundante da ação política deve ser compartilhado pelos indivíduos que compõe a sociedade democrática e justa.

A liberdade como não dominação é o princípio republicano da justiça. Ela oferece o critério objetivamente orientado (goal-oriented) para a dedução dos direitos básicos que deverão ser assegurados pelo Estado democrático de direito. Ela também funciona como critério para a avaliação consequencialista das ações do Estado em prol da interação social entre os cidadãos. $O$ critério objetivamente orientado (goal-oriented) significa que a liberdade republicana é o ideal a ser adotado e colocado em prática pelas instituições políticas.

O Estado estabelecerá o equilíbrio adequado entre as reivindicações dos cidadãos, no entanto, essas afirmações são entendidas, apenas na medida em que trata os cidadãos como iguais ao abordá-los - apenas na medida em que é expressivamente igualitário, como podemos afirmar, ao lidar com seus cidadãos (PETTIT, 2014, p. 79).

O termo consenquencialismo na teoria republicana é caracterizado como sendo o telos da ação do Estado. As instituições políticas deverão promover e maximizar o desenvolvimento da capacidade de escolha equânime entre os cidadãos. Nesta perspectiva teórica, o consequencialismo demonstra o ensejo de colocar em prática os ideais políticos e a ideia de liberdade como não-dominação. Como esclarece Lovett (2013, p. 8): “Pettit é consistentemente um consequencialista sobre a nãodominação: a liberdade da dominação é algo que devemos promover na concepção de instituições e práticas públicas, não é algo que devemos honrar como uma restrição".

4 Como explica Pettit (2012, p. 124): “O princípio republicano é extremamente modesto na caracterização da justiça pelas exigências de somente a igual liberdade, sem referência aos mais ricos e mais controversos dos valores invocados pelas teorias da justiça; é minimalista em termos requeridos para justificar as políticas apoiadas".

5 Pettit (2012, p. 123; 126; Ibid., 2014, p. 102) afirma que a justiça republicana se aproxima do modelo de justificação minimalista (justificatory minimalism), proposto por Joshua Cohen (2004), no que se refere a garantia das exigências básicas dos direitos humanos. A teoria republicana possibilita a diversidade das cosmovisões e projetos de vida segundo o seu ideal político de não-dominação. Esse ideal se situa em uma concepção de direitos humanos que seja universalmente compartilhada e ausente da influência das concepções de vida boa (ética), que orientam as tradições religiosas e grupos sociais comunitários. Nesse sentido, o ideal republicano pode assegurar os direitos básicos e a vida em conformidade com o telos dos grupos sociais eticamente orientados.

NETO, Alberto Paulo. A normatividade da teoria republicana da justiça. Griot : Revista de Filosofia, Amargosa, Bahia, v.16, n.2, p.115-131, dezembro/2017. 
O consequencialismo republicano se insere na perspectiva teleológica de buscar os meios para a promoção do ideal político. $O$ sistema jurídico se torna o meio para a promoção da igualdade jurídico-social. Nesta perspectiva, o objetivo é intensificar os locais de não-dominação e de capacitação dos cidadãos, tais como, o acesso à formação escolar e ao desenvolvimento de seus talentos. A concepção republicana compreende a ideia de Estado expansivo e inclusivista, as instituições políticas cuidam e equilibram as limitações que os cidadãos possam ter na vida social. Elas corrigem os desníveis de recursos e bens necessários para vida em liberdade.

A liberdade republica é intrínseca ao projeto institucional do Estado. Ela constitui e direciona as decisões e políticas públicas. Em Republicanism, Pettit (1997, p. 80-109) argumentou que a liberdade como não-dominação é o centro do ideário político republicano. O princípio da não-dominação é elegido a valor político supremo e o Estado tem o dever de promover esse valor da liberdade republicana ${ }^{6}$. Esse princípio normativo possibilita a gênese jurídica da Constituição política e social. Esse ideal político conta como bem pessoal, isto é, ele pertence ao indivíduo que está protegido na comunidade política. Ele pode ser desejado por todos como sendo o princípio fundante da vida política.

A não-dominação como bem pessoal se torna um valor instrumental porque ela tem a capacidade de gerar outros benefícios aos indivíduos. Obviamente, esse ideal político tem valor intrínseco porque ele pode ser almejado como princípio de orientação das ações na sociedade política. A não-dominação como bem instrumental tem o objetivo de proteger contra as formas de interferência arbitrária. Ela se estatui perante o poder alheio que tenha a capacidade de interferir na capacidade de escolha dos indivíduos. A não-dominação significa a ausência de qualquer interferência arbitrária ou a erradicação da capacidade de interferência. A liberdade nãodominação tem o intuito de reduzir as relações de subordinação e a capacidade alheia de interferência arbitrária.

No âmbito político, a liberdade republicana possibilita que os cidadãos tenham a capacidade de realizar os seus projetos de vida e que a sua voz possa ser ouvida na esfera pública. Nesse sentido, o ideal da não-dominação se estabelece como ideal político e de interesse público. Como dissemos, a liberdade não-dominação será o valor promovido pelo Estado. Esse conceito de liberdade não permite que os indivíduos busquem meios privados para a promoção da não-dominação. A obrigação de proteção é do Estado. A liberdade como não-dominação é o ideal que deve ser confiado à autoridade constitucional e não à capacidade individual de promovê-la. Os indivíduos devem participar da vida política para garantir a condição social de não-dominação. A participação política não é observada como intrinsecamente necessária, ela possui o valor instrumental. Isso quer dizer, os cidadãos republicanos participam da vida política no momento em que percebem a instauração de relações arbitrárias e utilizam a esfera pública para vocalizar e contestar as interferências injustificadas.

\footnotetext{
${ }^{6}$ Como explica Pettit (1997, p. 80): “Mas a tradição republicana não ofereceu apenas uma interpretação distinta do que envolve a liberdade. Ela lançou a liberdade como não-dominação no papel de valor político supremo e apoiou a suposição de que o raciocínio para um Estado coercivo e potencialmente dominante é simplesmente que, devidamente constituído, esse regime serve para promoção desse valor".
}

NETO, Alberto Paulo. A normatividade da teoria republicana da justiça. Griot : Revista de Filosofia, Amargosa, 
Na história do pensamento republicano, o ideal de não-dominação, no período pré-moderno, esteve circunscrito aos homens proprietários e possuidores do status civitatis (cidadania). Na modernidade, os republicanos arguiram que todos os seres humanos seriam iguais e o ideal político é destinado a todos. Pettit argumenta que a liberdade republicana, como bem supremo, seria possível de ser aderida pelas sociedades contemporâneas desenvolvidas, multiculturais e com independência da concepção de bem. Esse ideal político não é observado como restrição, ele é o objetivo da sociedade política. O Estado atuaria em conformidade com o valor da liberdade não-dominação ao promover a condição social republicana. Esse arranjo social e político do Estado republicano está sob o ideal igualitarismo expressivo.

\begin{abstract}
Mais concretamente, assumindo que as circunstâncias da justiça prescrevem a promoção do objetivo igualitário substancial de igualdade de status para todos. Isso não significa que os agentes dentro do sistema sociopolítico geralmente sejam licenciados para se comportar de forma oportunista ou estratégica, como já foi mencionado, ajustando suas respostas de acordo com o que eles pensam que seja melhor para promover esse objetivo (PETTIT, 2012, p. 123).
\end{abstract}

Os agentes políticos atuam para a realização do ideal republicano de liberdade. Em termos rawlsianos, a "estrutura básica" está configurada para a atuação dos indivíduos, funcionários ou cidadãos, em conformidade com o princípio republicano da justiça. Os indivíduos são obrigados a agir em conformidade com o direito e a interagirem segundo a ideia política de não-dominação. Essa é constitutiva da vida política e se institui como requisito para a realização da sociedade democrática.

Além disso, a liberdade republicana se estabelece como critério de avaliação para mensurar e comparar as sociedades em conformidade com a justiça social. $O$ objetivo é a avaliação comparativa entre as estruturas de sociedade que poderão auxiliar na orientação política do Estado e na remoção da injustiça social. Pettit propõe o teste do globo ocular (eyeball test) como critério de avaliação das situações sociais de subjugação e dominação social.

Embora possamos usar o princípio para identificar uma sociedade idealmente justa - digamos uma sociedade que seja apenas o suficiente para passar no teste de globo ocular - também podemos usá-la para avaliar e classificar os sistemas menos ideais com os quais o mundo real nos apresenta e acompanhar o progresso fragmentado dentro deles (PETTIT, 2012 , p. 124).

O teste do globo ocular possibilita que se faça a ponderação entre os tipos de sociedades que promovem a justiça social. Ele permite a proteção às escolhas básicas da vida e que os indivíduos não tenham motivo para se sentirem inferior em relação ao outro.

A teoria republicana se aproxima do modelo "focado nas realizações", proposto por Amartya Sen (2011), e se afasta do modelo "institucionalista transcendental", representado pela teoria rawlsiana. Amartya Sen (2011) elaborou a concepção de justiça que se orienta pela percepção das formas de injustiça no mundo

NETO, Alberto Paulo. A normatividade da teoria republicana da justiça. Griot : Revista de Filosofia, Amargosa, 
e a apresenta a possibilidade de resolução dos problemas sociais. Para ele, o diagnóstico das formas de injustiça deveria ser o ponto de partida de qualquer teoria da justiça. Ele ampara a sua teoria da justiça na imagem dos grandes líderes mundiais e movimentos sociais que tiveram uma causa: a remoção da injustiça na sociedade. $\mathrm{O}$ senso de (in)justiça impeliu os atores sociais a realizarem as mudanças políticas e jurídicas.

É correto pressupor que os parisienses não teriam tomado de assalto a Bastilha, que Gandhi não teria desafiado o império onde o sol costumava não se pôr, que Martin Luther King não teria combatido a supremacia branca na "terra dos homens livres e lar dos bravos", não fosse seu senso das injustiças manifestas que poderiam ser vencidas. Eles não estavam tentando alcançar um mundo perfeitamente justo (mesmo que não houvesse nenhum acordo sobre como seria tal mundo), mas o que queriam era remover claras injustiças até onde pudessem (SEN, 2011, p. 9-10).

A teoria da justiça de Sen, denominada comparação focada nas realizações, se estrutura em três aspectos: $i$. O fundamento da teoria é oferecido pela argumentação racional no domínio prático. $O$ debate tem o objetivo de identificar as formas de redução da injustiça e a promoção da justiça. Esse quesito é contrário à perspectiva idealista de sociedade justa (institucionalismo transcendental); ii. A teoria da justiça se fundamenta pelo acordo alcançado por meio de argumentos fundamentados e tem uma pluralidade valorativa e, iii. A injustiça é observada como passível de ser corrigida e se situa como transgressão de comportamento e não como sendo o defeito das instituições. Por isso, essa concepção de justiça analisa o modo como vivem as pessoas e não a estrutura das instituições. Sen realiza a contundente crítica à teoria rawlsiana da justiça. Segundo ele, a teoria de Rawls se configura com o objetivo de estabelecer as "instituições justas" e atribui uma função secundária ao comportamento dos indivíduos. A perspectiva focada nas capacidades tem o intuito de desenvolver a concepção de justiça em termos de vida humana e da liberdade que as pessoas podem respectivamente exercer. "Instituições e regras são, naturalmente, muito importantes para influenciar o que acontece, além de serem parte integrante do mundo real, mas as realizações de fato vão muito além do quadro organizacional e incluem as vidas que as pessoas conseguem - ou não — viver" (SEN, 2011, p. 48).

Nesse sentido, a teoria da justiça focada nas realizações tem o interesse centrado na vida humana e suas relações sociais. Ela pressupõe que os indivíduos devem se desenvolver a partir de sua capacidade de escolha. A teoria e prática de uma concepção de justiça tem que proporcionar essa possibilidade de realização da vida humana.

\footnotetext{
A liberdade de escolha nos dá a oportunidade de decidir o que devemos fazer, mas com essa oportunidade vem a responsabilidade pelo que fazemos — na medida em que são ações escolhidas. Uma vez que uma capacidade é o poder de fazer algo, a responsabilidade que emana dessa capacidade - desse poder - é uma parte da perspectiva das capacidades, e isso pode abrir espaço para demandas do dever — o que pode ser genericamente chamado de exigências deontológicas (SEN, 2011, p. 49).
}

NETO, Alberto Paulo. A normatividade da teoria republicana da justiça. Griot : Revista de Filosofia, Amargosa, 
De acordo com Pettit, a teoria republicana da justiça se aproxima do modelo proposto por Sen (2011) primeiramente porque ela se constitui como teoria consequencialista que objetiva a redução da dominação social e das injustiças (i) e não realiza a idealização sobre a natureza humana ou instituições políticas. Em comparação com a teoria rawlsiana da justiça, Pettit afirma que o modelo do liberalismo político realiza a idealização das instituições políticas ao estabelecer o padrão de realização pela concepção de justiça. Ao contrário, o modelo republicano se orienta pela promoção do ideal de não-dominação e a restrição de escolhas que não possam ser protegidas por meio de leis públicas.

\begin{abstract}
Os filósofos políticos prosseguem muitos estudos abstratos que têm pouca conexão direta à vida pública, incluindo exercícios na análise conceitual, a teoria institucional, a modelagem formal e história intelectual, bem como, as experiências de pensamento nas exigências da justiça perfeita. Nós mesmos temos investido em tais estudos, muitas vezes a partir do ponto de vista do republicanismo cívico, e vemos grande valor em sua busca intelectual (MARTÍ \& PETTIT, 2010, p. 135-6).
\end{abstract}

O objetivo é que a reflexão republicana se aproxime da vida real e utilize as categorias de sua teoria para a aplicação na sociedade democrática. Os pressupostos normativos da filosofia política devem estar a serviço das instituições que estabeleçam o critério de não-dominação. De acordo com Martí \& Pettit (2010), a estrutura da filosofia política deve ser igualmente compartilhada pelos membros da sociedade. Os princípios devem ser universalmente acessíveis e aceitáveis (1), os pressupostos devem ser realistas e possibilitar a compreensão de suas determinações (aspecto cognitivo) e ter a capacidade de motivar ao cumprimento das determinações (aspecto motivacional) (2), e o ideal deve possuir a sinergia necessária para conduzir com lealdade os cidadãos ao engajamento na vida social e política (3). Ele não deve permitir que as pessoas fossem complacentes ou indiferentes com as situações de injustiça.

Por isso, a concepção republicana de justiça dialoga com a teoria focada nas capacidades de Sen para perceber as formas de subjugação na sociedade. $O$ impedimento da realização das capacidades humanas em liberdade se torna o problema social que exige a estrutura jurídica do Estado. As instituições políticas terão a finalidade de corrigir essa disparidade social. Os cidadãos possuem a capacidade cognitiva e motivacional para agir em conjunto para contestar as situações de dominação social.

\title{
As exigências da justiça republicana
}

A liberdade como não-dominação é postulado como valor supremo da teoria republicana da justiça. Ela permite que outros valores possam ser deduzidos do princípio republicano. A justiça se refere à estrutura institucional que o Estado poderá oferecer aos cidadãos para a manutenção da igualdade e das condições para o exercício da capacidade de escolher em liberdade.

“A liberdade como não-dominação não é o único valor na política, mas na versão defendida aqui serve ao papel de entrada: se pagarmos o preço de

NETO, Alberto Paulo. A normatividade da teoria republicana da justiça. Griot : Revista de Filosofia, Amargosa, 
garantir a liberdade como não-dominação em uma medida adequada, teremos pago o suficiente para garantir a justiça social e a legitimidade política (...)" (PETTIT, 2012, p. 127).

A estrutura institucional do modelo republicano de justiça comporta elementos substantivos para a promoção da liberdade. Ela tem o objetivo primordial de eliminar as relações de domínio entre indivíduos ou grupos sociais. Por um lado, a estrutura organizacional do Estado proporciona os requisitos necessários para o desenvolvimento das capacidades dos indivíduos, por outro lado, ela protege contra as formas de dominação privada (dominium).

\begin{abstract}
Imagine um grupo de pessoas que formam uma minoria numérica em uma sociedade política, e que está estruturalmente desfavorecidodesfavorecido, isto quer dizer, por institucionalizadas desigualdades de recursos, oportunidades e na capacidade social para agir-vis-à-vis - pela maioria da população. Vamos estipular que essas pessoas têm desenvolvido ao longo do tempo, talvez, em resposta às experiências compartilhadas de subjugação e/ou marginalização, práticas e instituições com as quais se identificam como membros deste grupo e que as diversas experiências de sua participação como membros deste grupo particular em algum sentido profundo relativamente duradouro são constitutivas de suas identidades pessoais (HAYWARD, 2011, p. 469).
\end{abstract}

A promoção da liberdade republicana implica o reconhecimento dos direitos das minorias e que suas exigências sejam ouvidas pelos representantes políticos e pelo grupo majoritário. Clarice R. Hayward (2011) oferece a resposta que se aproxima do modelo republicano de justiça social. Ela propõe que o ideal de nãodominação possua duas características: i. A interação não-dominada entre agentes (inter-agentive nondomination), a capacidade que os atores políticos têm de se relacionar em igualdade de poder na esfera pública e, ii. A não-dominação sistêmica (systemic nondomination): a interação entre os participantes se realiza nas instituições políticas pelo princípio da impessoalidade.

Eu defino a liberdade política como não-dominação: é o estado das relações de poder em que todos são socialmente habilitados a participar efetivamente em fazer e refazer as instituições, as políticas, as leis e as outras normas sociais que definem seus termos. A liberdade política, assim entendida, se obtém quando todos os participantes, em uma relação de poder, são livres do domínio por outros agentes que têm poder desproporcional para definir os termos da relação e quando os participantes da relação de poder, considerados em conjunto, alcançam a agência coletiva vis-à-vis desses termos (HAYWARD, 2011, p. 478).

De acordo com Clarisse Hayward, sob a influência de Pettit (1997, p. 52), a liberdade como não-dominação tem a característica social, os atores sociais interagem e estabelecem as instituições políticas. Ela é relativa porque varia em sua intensidade segundo o contexto social e a não-dominação pode ser o produto das escolhas individuais. Ela observa a condição social dos indivíduos e a proteção que seja necessária para a vida em liberdade.

NETO, Alberto Paulo. A normatividade da teoria republicana da justiça. Griot : Revista de Filosofia, Amargosa, 
A condição social de liberdade deve ser respaldada pela infraestrutura estatal. Essa infraestrutura tem objetivo de proteger e capacitar os indivíduos para que eles estejam aptos ao exercício da livre-escolha. Ela se estabelece pelos aspectos institucionais e materiais. $O$ primeiro aspecto tem o objetivo de oferecer a capacitação necessária para a realização de escolhas livres, tais como o acesso à educação e à formação. $\mathrm{O}$ segundo aspecto tem o intuito de proteger os indivíduos no que se refere às condições necessárias para o desenvolvimento da vida social e política: a sustentabilidade ambiental, o ambiente urbano adequado e a organização estrutural da cidade.

A perspectiva republicana observa a necessidade de oferecer seguros sociais aos cidadãos em casos de vulnerabilidade social. Os seguros sociais podem abranger a assistência social e previdenciária, o auxílio médico e jurídico. Esses são acionados em caso de calamidades e reveses na vida. Ademais, a estrutura jurídica deve se preocupar com os casos de transgressão ao ordenamento jurídico, nisto é encarregada a justiça criminal. "Isso proporcionaria as capacidades básicas de funcionamento de todos os cidadãos, como descreveram Sen (1985) e Nussbaum (2006), e permite que as pessoas olhem os outros nos olhos, sem motivo de medo ou deferência - ou, pelo menos, sem qualquer razão ao perigo de interferência" (PETTIT, 2012, p. 126).

Martha Nussbaum (2006, p. 77-8) descreveu o "decálogo" das capacidades humanas. Segundo Nussbaum, os seres humanos devem ser capazes de viver até o limite da vida humana e não terem o tempo de sua vida reduzida prematuramente ou sem dignidade (1). A vida humana deve gozar de boa saúde e das condições necessárias para uma vida saudável (2). Os seres humanos devem ter o direito de locomoção e protegida a sua integridade física (3). Os sentidos, a imaginação e o pensamento são formas próprias da humanidade e devem ser cultivadas pela educação e a formação artística e pelo uso de sua liberdade de expressão (4). As emoç̃̃es devem ser protegidas para que não se desenvolvam pelo medo e ansiedade. Para isto, elas devem ser incentivadas pela forma de associação humana, fundada na solidariedade (5). O desenvolvimento da racionalidade prática deve ser capaz de formar uma concepção do bem, a garantia dos direitos e a tolerância aos outros (6). Os seres humanos devem ser capazes de conviver e se preocuparem com o Outro. Assim como, estabelecer as formas de filiação para o respeito mútuo e a nãodiscriminação (7). A capacidade de se preocupar com as outras espécies animais e vegetais e o meio ambiente deve ser desenvolvida nos seres humanos (8). Os seres humanos devem ser capazes de brincar, jogar e desfrutar de atividades recreativas (9). Os seres humanos devem ser capazes de participar da vida política e terem condições materiais para serem felizes e exercerem a suas escolhas livres (10).

A perspectiva das capacidades, representada por Sen (2011) e Nussbaum (2006), exerce forte influência na concepção normativa da justiça republicana que foi desenvolvida por Philip Pettit. O rol das capacidades humanas representa os direitos básicos que devem ser garantidos pelo Estado aos seus cidadãos. O elenco das capacidades é a referência para observar as injustiças nas sociedades reais. A ausência do desenvolvimento dessas capacidades se torna obstáculo para que os indivíduos possam desfrutar da liberdade como não-dominação em sua plenitude. $O$ Estado republicano deve possuir a estrutura jurídica que impossibilite o estabelecimento de relações arbitrárias pelos indivíduos mais afortunados.

NETO, Alberto Paulo. A normatividade da teoria republicana da justiça. Griot : Revista de Filosofia, Amargosa, 
A teoria republicana da justiça não pretende corrigir todos os desvios sociais e econômicos que afetam a vida do indivíduo. $O$ campo de extensão desta teoria da justiça é menor comparado com as teorias igualitárias. Ela não objetiva a igualdade material. A abordagem republicana comporta determinada desigualdade socioeconômica que não seja prejudicial ao desenvolvimento da liberdade ou que coloque os cidadãos em condição social de humilhação ou inferioridade.

\title{
O Estado republicano e sua estrutura jurídica-social
}

\begin{abstract}
Quando, numa cidade, dizem alguns filósofos, um ou muitos ambiciosos podem elevar-se, mediante a riqueza ou o poderio, nascem os privilégios de seu orgulho despótico, e seu jugo arrogante se impõe à multidão covarde e débil. Mas quando o povo sabe, ao contrário, manter suas prerrogativas, não é possível a esses encontrar mais glória, prosperidade e liberdade, porque então o povo permanece árbitro das leis, dos juízes, da paz, da guerra, dos tratados, da vida e da fortuna de todos e de cada um; então, e só então, é a coisa pública coisa do povo (Cícero, Da República, Livro I, XXXII).
\end{abstract}

A garantia da liberdade na civitas implica o equilíbrio do poder de influência entre os cidadãos. A força dos mais afortunado ou o grupo numericamente maior tem que ser contida para que a república não se torne plutocracia ou tirania majoritária. A legislação deve estar à serviço da igualdade. Ela é o elo entre os cidadãos e suas reivindicações de respeito mútuo. Cícero propõe que a estabilidade da República está na forma que ela consegue garantir a relação de equidade e a impessoalidade nas exigências civis. Essa aposta republicana não pode prescindir do reconhecimento da validade do ordenamento jurídico e que a finalidade do Estado de direito é fundada no consentimento jurídico e na utilidade social, a garantia da equidade e isonomia.

\footnotetext{
"Sendo a lei o laço de toda sociedade civil, e proclamando seu princípio a comum igualdade, sobre que base assenta uma associação de cidadãos cujos direitos não são os mesmos para todos? Se não se admite a igualdade da fortuna, se a igualdade da inteligência é um mito, a igualdade dos direitos parece ao menos obrigatória entre os membros de uma mesma república. Que é, pois, o Estado, senão uma sociedade para o direito?" (Cícero, Da República, Livro I, XXXII).
}

A questão da desigualdade social (material) e a garantia da igualdade jurídica é tema relevante na filosofia política. Por exemplo, Kant (1988), no opúsculo "Sobre a expressão corrente: isso pode ser correcto na teoria, mas nada vale na prática" (1793), argumentou que a existência da maior desigualdade (física, social ou econômica) possível não afetaria a igualdade jurídica, com a exceção de que o desnível social não transgredisse a legislação ou colocasse o súdito menos favorecido em condição jurídica inferior ao súdito mais afortunado. $O$ sistema de direitos estaria organizado a permitir que os indivíduos, como súditos, pudessem desenvolver seus talentos e a sua fortuna. $O$ direito teria o objetivo de impedir que os membros da comunidade política se colocassem como obstáculos à realização desta finalidade. Nas palavras de Kant (1988, p. 76-7):

NETO, Alberto Paulo. A normatividade da teoria republicana da justiça. Griot : Revista de Filosofia, Amargosa, 
“(...) esta igualdade universal dos homens num Estado, como seus súbditos, é totalmente compatível com a maior desigualdade na qualidade ou nos graus da sua propriedade, quer na superioridade física ou intelectual sobre os outros ou em bens de fortuna que lhe são exteriores e em direitos em geral (de que pode haver muitos) em relação aos outros; de maneira que o bem-estar de um depende muito da vontade do outro (o do pobre depende da do rico), um deve obedecer (como a criança aos pais, ou a mulher ao homem) e o outro dá-lhe ordens, um serve (como jornaleiro), o outro paga, etc.".

A garantia da condição social de não-dominação é correlata à estrutura jurídico-social. O Estado republicano tem a incumbência de proteger os cidadãos perante a influência que os indivíduos mais afortunados possam ter em relação aos indivíduos menos favorecidos. Nas democracias contemporâneas, o poder de influência dos mais ricos e das corporações financeiras prevalece sobre a capacidade de escolha dos mais pobres (indivíduos, grupos sociais ou países). Por isso, a abordagem republicana tem que refletir se seu princípio normativo e os recursos e proteções, derivados da liberdade política, é suficiente para proteger os indivíduos diante do poderio dos mais abastados?

Diante disso, o Estado deve tratar as pessoas como iguais - deve ser expressivamente igualitário - em promover a sua liberdade como nãodominação, com base em leis e normas públicas, dentro da esfera das liberdades básicas. Esta abordagem se alinha com a tradição do pensamento republicano, conectando-se com a ideia que Cícero $(1998,21)$ expressou a liberdade e a igualdade: "Nada pode ser mais doce que a liberdade. No entanto, se não for inteiramente igual, não é liberdade para todos" (PETTIT, 2014, p. 81).

As normas jurídicas podem exercer a função de equilíbrio das forças e de poder na sociedade democrática. Elas podem oferecer a regularidade comportamental necessária para a vida social em liberdade. As leis auxiliam o controle social daqueles que queiram exercer a influência indevida ou prejudicial aos grupos minoritários ou menos influentes.

\footnotetext{
"Na medida em que a lei é o trabalho de um Estado legítimo, ele se conectará com os hábitos da opinião pública e buscará o apoio em normas endossadas pela comunidade. E, ao fazer isso, pode estabelecer aos cidadãos o status arraigado - seu status público como pessoas livres - que seja suficiente como baluarte contra as vantagens que podem ter os ricos" (PETTIT, 2012, p. 127-8).
}

\footnotetext{
${ }^{7} \mathrm{O}$ nível de provisão que enseja a teoria republicana da justiça é compatível com a desigualdade social. Essa condição social não deve ser impedimento à capacidade dos indivíduos em se olharem sem qualquer motivo para medo ou deferência. Como explica Pettit (2014, p. 99): "Sob a teoria republicana da justiça social, as leis e normas da sociedade devem identificar o conjunto adequado de liberdades básicas, e os recursos e proteções até o ponto em que, intuitivamente, não há mais exigências a serem feitas: é o ponto em que as pessoas contam como iguais no gozo da liberdade como não-dominação. Enquanto possa haver o suficiente para permitir as diferenças em recursos e proteções privadas, todos devem igualmente desfrutar de um nível adequado de tratamento no exercício dessas liberdades".
}

NETO, Alberto Paulo. A normatividade da teoria republicana da justiça. Griot : Revista de Filosofia, Amargosa, 
As normas jurídicas se estabelecem pelas expectativas de cumprimento e a aceitação geral. Elas representam a aprovação de determinado comportamento ou anseio que a conduta benéfica à comunidade política e ao indivíduo seja cumprida por todos. Pettit se apoia no adágio de Adam Smith para compreender a intangibilidade das normas jurídicas e a tendência humana ao desejo de vida social aprazível.

\begin{abstract}
A Natureza quando formou o homem para a sociedade dotou-o de um desejo original de agradar e uma aversão original para ofender seus irmãos. Ela ensinou-o a sentir prazer em seu favor, e a dor em seu aspecto desfavorável. Ela rendeu sua aprovação mais lisonjeira e mais agradável para ele por seu próprio bem; e sua desaprovação mais mortificante e mais ofensiva (Smith apud PETTIT, 2012, p. 128).
\end{abstract}

As normas jurídicas atuariam com a finalidade de promover a conduta que beneficia a vida em comunidade e elas coibiriam os tipos de comportamentos que são prejudiciais e danos aos indivíduos. Elas possuem a coerção necessária para corrigir os desníveis de poder de influência na sociedade democrática. $O$ ordenamento jurídico tem que almejar a sua validade pelo ideal político que ele irá promover. A aceitação geral está amparada na aproximação com a ideia regulativa de nãodominação.

\begin{abstract}
A força secreta da lei é que, se for bem moldada e bem apoiada - se for relativamente justa e legítima -, então, pode recrutar normas benéficas e comunais à causa de sua execução (...). Corretamente promulgada e defendida, de fato, ela também pode ganhar reforço normativo, não precisa mais confiar na força da espada pública, na velha metáfora, para conquistar a conformidade entre os cidadãos (PETTIT, 2012, p. 128-9).
\end{abstract}

No capítulo intitulado Checking the Republic, contido na obra Republicanism (1997), Pettit se empenha em analisar a questão da estabilidade e o controle na República. Como sabemos, o Estado republicano e sua estrutura institucional tem o objetivo de reduzir as formas arbitrárias de dominação. No entanto, a conduta humana pode se inclinar ao descumprimento da legislação. $O$ problema da estabilidade se refere às formas que o Estado tem disponível para conter os desvios de conduta e incentivar as boas práticas de cidadania. Pettit observa que os cidadãos e funcionários do Estado estão suscetíveis à corrupção. No entanto, é possível perceber que os eles podem ser motivados ao cumprimento da lei e formarem a disposição ao civismo. As ações empreendidas pelo Estado para conter os desvios de conduta estarão sob a obrigação de estabelecer as restrições necessárias ao estímulo da virtude cívica. Todavia, elas estão sob o dilema institucional de que o excesso de restrições impedirá o desenvolvimento da virtude nos cidadãos ou a ausência de restrições terá o predomínio da conduta viciada.

\footnotetext{
A tradição republicana sempre adotou essa conclusão, todavia, ela também insistiu na importância da virtude. Ele abraçou a necessidade, não apenas para um padrão republicano de direito e democracia, mas para um regime de freios e contrapesos (checks and balances), como eles vieram a ser chamados (PETTIT, 1997, p. 212).
}

NETO, Alberto Paulo. A normatividade da teoria republicana da justiça. Griot : Revista de Filosofia, Amargosa, 
O modelo republicano é enfático na virtude cívica. $\mathrm{O}$ aperfeiçoamento das instituições públicas procede do adequado emprego das medidas de contenção de arbitrariedades (check and balance). Elas têm que ser direcionadas aos cumpridores da lei e possibilitar o crivo dos agentes públicos que representarão o ideal de civismo.

\begin{abstract}
"O fato de que a lei pode desfrutar deste tipo de apoio significa que, quando assegura o recurso e a proteção dos indivíduos, pode ser suficientemente poderosa, em princípio, para alcançar o equilíbrio nas posições relativas das pessoas, mesmo quando esses indivíduos variam consideravelmente nos recursos privados à disposição deles" (PETTIT, 2012, p. 129).
\end{abstract}

A diferença de recursos e bens não é impedimento para a concessão da igualdade de liberdade. A igualdade material não é o requisito necessário para que os indivíduos estejam em condição social de igual não-dominação. Em outras palavras, a desigualdade social não será obstáculo à liberdade, com exceção, as relações que possam ser caracterizadas como formas de domínio pela condição financeira. $O$ Estado republicano deve possuir a estrutura jurídica que possibilite que aos cidadãos a proteção da sua liberdade e que possam reivindicar a reparação em casos que tenham sofrido danos ao desenvolvimento de suas capacidades.

\title{
Considerações Finais
}

A liberdade republicana como princípio normativo da justiça estabelece sob a tríade atuação: ela é o fundamento para as decisões políticas em conformidade com o objetivo de promoção da igual liberdade (i); o ideário político de não-dominação é postulado como critério objetivamente orientado (goal-oriented) para a normatização dos direitos básicos (ii); e, a liberdade como não-dominação funciona como critério de avaliação, mediante o emprego do teste do globo ocular, para o reconhecimento das formas de vida subjugadas e dominadas na vida social e pública (iii).

A teoria republicana da justiça pressupõe a igualdade de tratamento e consideração entre os cidadãos. Ela se fundamenta pelo ideal de não-dominação e preceitua que a estrutura jurídica deve favorecer o desenvolvimento das capacidades humanas em sua plenitude. Os indivíduos não estão em igualdade de recursos e bens para o cultivo de seus talentos e capacidades. A abordagem republicana postula que as instituições políticas deverão realizar as compensações necessárias para que as relações sociais não se caracterizem pela humilhação ou marginalização daquele que possua uma condição social-financeira menor.

O consequencialismo do modelo republicano denota a ensejo de realizar os pressupostos normativos de uma filosofia política que não perdeu a conexão entre a teoria e práxis. A teoria política republicana está preocupada em oferecer o diagnóstico da sociedade e juntamente oferecer o prognóstico necessário para o estabelecimento das relações sociais não-dominadas.

A construção da sociedade democrática tem que como parâmetro a igualdade social e jurídica entre os seus cidadãos. A hipótese da permanência de condições de subjugação é impedimento para o exercício equânime dos direitos políticos. Uma vez

NETO, Alberto Paulo. A normatividade da teoria republicana da justiça. Griot : Revista de Filosofia, Amargosa, 
que os indivíduos humilhados e subjugados irão produzir as condições de dominação social na vida política. O republicanismo de Philip Pettit é enfático em demonstrar que a sociedade democrática necessita de condições justas para a sua efetivação. Por isso, a garantia da justiça ou a condição social de não-dominação para todos se torna a conditio sine qua non para o exercício da vida política ou não teremos a democracia nos moldes republicanos. 


\section{Referências bibliográficas}

CÍCERO, Marco Tulio. Opere politiche e filosofiche di M. Tullio Ciceroni (Volume primo Lo Stato, Le leggi, I doveri). Torino: Unione Tipografico - Editrice Torinese, 1974 .

. Da República. São Paulo: Abril Cultural, 1985 (Coleção Os Pensadores).

On the Commonwealth and On the Laws. Cambridge: Cambridge University Press, 1999.

COHEN, Joshua. Minimalism About Human Rights: The Most We Can Hope For. Journal of Political Philosophy, v. 12, n. 2, 2004, p. 190-213.

DIGESER, Elizabeth Depalma. Citizenship and the Roman Res publica: Cicero and a Christian Corollary. In: WEINSTOCK, Daniel; NADEAU, Christian (Eds.). Republicanism: History, Theory and Practice. London: Frank Cass Publishers, 2004, p. 5-19.

FOX, Matthew. Cicero's Philosophy of History. Oxford: OUP, 2007.

HAYWARD, Clarissa Rile. What Can Political Freedom Mean in a Multicultural Democracy? On Deliberation, Difference and Democratic Government. Political Theory, v. 39, n. 4, 2011, p. 468-97.

HOLTON, James E. Marco Tulio Cicerón. In: STRAUSS, Leo; CROPSEY, Joseph (Comp.) Historia de la filosofia politica. México: Fondo de Cultura Económica, 1993, p. 158-176.

HONOHAN, Iseult. Civic Republicanism. London/New York: Routledge, 2002.

KANT, Immanuel. Sobre a expressão corrente: isso pode ser correcto na teoria, mas nada vale na prática (1793). In: . A paz perpétua e outros opúsculos. Tradução de Artur Morão. Lisboa: Edições 70, 1988, p. 57-102.

LOVETT, Frank. Freedom, justice, and legitimacy in Pettit's On the People's Terms. Annual Meeting of the American Political Science Association, August 29th September 1st, 2013. Disponível em: < https://papers.ssrn.com/sol3/papers.cfm?abstract_id=2300125>.

MARTÍ, José Luis; PETTIT, Philip. A Political Philosophy in Public Life: Civic Republicanism in Zapatero's Spain. Princeton: Princeton University Press, 2010.

MARTÍ, José Luis; SELME, Hugo, Three Comments on Philip Pettit's On the People's Terms. Philosophy and Public Issues (New Series), v. 5, n. 2, 2015, p. 25-42. MORFORD, Mark. The roman philosophers: From the time of Cato the Censor to the death of Marcus Aurelius. London/New York: Routledge, 2002.

NUSSBAUM, Martha. Frontiers of Justice. Harvard: Harvard University Press, 2006.

PAULO NETO, Alberto. Entre o consenso e a contestação no Estado democrático de direito: Uma interlocução entre a Teoria democrática de J. Habermas e P. Pettit. 2015. 198f. Tese (Doutorado em Filosofia) - Faculdade de Filosofia, Letras e Ciências Humanas. Departamento de Filosofia, Universidade de São Paulo, São Paulo, 2015. - A análise de Jürgen Habermas sobre a tensão entre direitos humanos e soberania popular na teoria do direito de Immanuel Kant. 2009. Dissertação (Mestrado em Filosofia) - Universidade Federal de Santa Catarina.

NETO, Alberto Paulo. A normatividade da teoria republicana da justiça. Griot : Revista de Filosofia, Amargosa, 
PETTIT, Philip. Just freedom: A moral compass for a complex world. New York/London: W. W. Norton \& Company, 2014.

. On the people's terms: a republican theory and model of democracy. Cambridge: Cambridge University Press, 2012. . The Domination Complaint. Nomos, n. 46, 2005, p. 87-117. . Republicanism: a theory of freedom and government. Oxford: Clarendon Press, 1997.

. Consequencialism. In: SINGER, Peter (Ed.). A Companion to Ethics. Oxford: Blackwell Publishers, 1991, p. 231-238.

SEN, Amartya. A ideia de Justiça. São Paulo: Companhia das Letras, 2011.

STROH, Wilfried. Cicero: Redner, Staatsmann, Philosoph. München: Verlag C. H. Beck, 2008.

Autor(a) para correspondência: Alberto Paulo Neto, Pontifícia Universidade Católica do Paraná, R. Imac. Conceição, 1155, Prado Velho, CEP 80215-901, Curitiba - PR, Brasil. apnsophos@yahoo.com.br 